\title{
First-Order ARMA Type Fuzzy Time Series Method Based on Fuzzy Logic Relation Tables
}

\author{
Cem Kocak \\ School of Health, Hitit University, 19000 Corum, Turkey \\ Correspondence should be addressed to Cem Kocak; cemkocak@hotmail.com
}

Received 2 July 2013; Revised 1 August 2013; Accepted 3 August 2013

Academic Editor: Ming Li

Copyright ( 2013 Cem Kocak. This is an open access article distributed under the Creative Commons Attribution License, which permits unrestricted use, distribution, and reproduction in any medium, provided the original work is properly cited.

\begin{abstract}
Fuzzy time series approaches have an important deficiency according to classical time series approaches. This deficiency comes from the fact that all of the fuzzy time series models developed in the literature use autoregressive (AR) variables, without any studies that also make use of moving averages (MAs) variables with the exception of only one study (Egrioglu et al. (2013)). In order to eliminate this deficiency, it is necessary to have many of daily life time series be expressed with Autoregressive Moving Averages (ARMAs) models that are based not only on the lagged values of the time series (AR variables) but also on the lagged values of the error series (MA variables). To that end, a new first-order fuzzy ARMA(1,1) time series forecasting method solution algorithm based on fuzzy logic group relation tables has been developed. The new method proposed has been compared against some methods in the literature by applying them on Istanbul Stock Exchange national 100 index (IMKB) and Gold Prices time series in regards to forecasting performance.
\end{abstract}

\section{Introduction}

Fuzzy time series approaches not necessitating many of the limitations seen in classical time series approaches such as linearity, stationarity, and number of observations have increased the interest towards these approaches. Fuzzy time series concept first mentioned in the literature by Song and Chissom [1] was based on the fuzzy set theory of Zadeh [2]. Song and Chissom [3,4] divided fuzzy time series into two groups, namely, time variant and time invariant. A vast majority of the studies in the literature are methods proposed for solving time invariant fuzzy time series. Because models are significantly effective on the forecasting performances during the determination of fuzzy relations stage, different approaches have been proposed in the literature. In the studies of Song and Chissom $[1,3,4]$, relations are determined with complex matrix operations. In order to eliminate this complexity, a new first-order fuzzy time series model has been proposed where fuzzy logic group relation tables are used in Chen's [5] study with simplified operations not necessitating complex matrix processes. This approach of Chen [5] is used in many studies due to its positive effect on forecasting performance. Therefore, Chen [6] developed a new approach by using the fuzzy logic relation tables also in high-order fuzzy time series models. Because the methods proposed in the studies of Chen $[5,6]$ necessitate obtainment of many fuzzy logic group relation tables, they require numerous operations. Thus, studies where fuzzy relations are determined with artificial neural networks are commonly seen. Some Studies where artificial neural networks are used for determining fuzzy relations may be listed as the studies of Huarng and Yu [7], Aladag et al. [8], Yu and Huarng [9], and Yolcu et al. [10].

In majority of the studies in the literature, interval lengths are specified intuitively. In his study, Huarng [11] has proposed two separate approaches based on average and distribution to specify optimal interval length. The optimal interval lengths determined by the approach of Huarng [11] may be obtained to be very large values. Thus, Egrioglu et al. [12] proposed approaches based on the optimisation of interval length. Different from these studies, Huarng and Yu [13] proposed an approach based on ratio with interval length varying exponentially instead of determining a fixed interval length in the solution of first-order fuzzy time series. 
Determining the ratio in the study of Huarng and Yu [13] requires many complex calculations. Therefore, Yolcu et al. [14] proposed a new approach that improves the approach of Huarng and $\mathrm{Yu}$ [13], based on the optimisation of ratio.

There are 3 most commonly used models in the analysis of single variable time series in classical time series approach. These are autoregressive (AR), moving averages (MAs), and mixed autoregressive moving averages (ARMAs) models. However, fuzzy time series methods developed in the literature focus on the AR model of the classical time series theory, without any study conducted on the utilisation of MA and ARMA models except Uslu et al. [15], Alpaslan et al. [16], and Aladag et al. [17]. These studies [15-17] on the other hand are methods that have been proposed for the solution of seasonal time series. No study has been made on the inclusion of error variable to the model for nonseasonal fuzzy time series with the exception of Egrioglu et al. [18] study. This study [18] is the first study developed as first order fuzzy ARMA type model based on particle swarm optimization for the solution of nonseasonal time series in the literature. All of the models in the literature have mentioned issues such as the use of universe of discourse partitioning, membership order, model order, and artificial intelligence approaches. However, the fuzzy time series models proposed in the literature only including AR variables which may lead to a model specification error. In many modelling of the real life time series, MA variables are also required. In this sense, use of only AR variables for the solution of fuzzy time series requiring also MA variables for modelling becomes insufficient regarding the forecasting performance.

For the purpose of eliminating the adverse effects mentioned, a solution algorithm for a new first-order fuzzy $\operatorname{ARMA}(1,1)$ time series forecast model where fuzzy relations are determined based on fuzzy logic group relations has been proposed in this study. The logic for determining fuzzy relations in the proposed method is an approach similar to that of the study of Chen [5], aiming to show that the forecasting performance can be significantly improved when the model specification error in the method of Chen [5], accepted as a fundamental approach in literature, is eliminated. For many real life time series, performance can be increased through the use of high-order fuzzy time series models due to the ability to realise solution with more information. However, because the proposed fuzzy ARMA $(1,1)$ model uses a second variable (error variable), it utilises more information to the extent it eliminates the model error, and although just a first order model, it occurs to have a better forecasting performance than that of high order fuzzy time series methods.

In this paper, the time series which were used in application are examined according to long-range dependence. Time series can be classified short range or long-range dependence time series. Many time series have long-range dependence. The long-range dependence time series are forecasted different methods like autoregressive fractionally integrated moving average (ARFIMA). ARFIMA models have fractionally differencing parameter. First studies were concerned with estimation of fractional differencing parameter in fractional white noise processes. $R / S$ statistic was proposed in Hurst [19]. The other important studies about fractional differenced processes are Li and Zhao [20, 21], Li [22], Stanley et al. [23], Werner [24], Beran [25], Ivanov et al. [26], Podobnik et al. [27], Zevallos and Palma [28], and Bhansali and Kokoszka [29].

In the second section of the study, basic definitions regarding fuzzy time series have been provided. In the third section, the proposed fuzzy time series forecasting model has been defined and the solution algorithm has been provided. In the fourth section, the proposed method has been applied to Istanbul Stock Exchange (IMKB) national 100 index time series and gold prices in 2009 taken from Turkish Republic Central Bank (TCMB) website, comparing it to some other methods in the literature regarding forecasting performance. An in-depth comparison has been made in this section. In the fifth section, the study has been summed up by discussing the results obtained.

\section{Definition of Fuzzy Time Series}

Fuzzy time series concepts and definitions have been developed in accordance to the lagged variables of times series (AR, autoregressive) in all studies conducted in the literature. Main time series definitions developed using AR variables are listed below.

Definition 1. Let $X(t)(t=\ldots, 0,1,2, \ldots)$, a subset of real numbers, be the universe of discourse on which fuzzy sets $f_{j}(t)$ are defined. If $F(t)$ is a collection of $f_{1}(t), f_{2}(t), \ldots$ then $F(t)$ is called a fuzzy time series defined on $X(t)[1,3,4]$.

Definition 2. Let us consider the fuzzy relation between $R(t, t-1), F(t-1)$, and $F(t)$. For any $t$ value, if $R(t, t-1)$ is independent from $t$, then $R(t, t-1)=R(t-1, t-2)$. In this case, $F(t)$ is called the time invariant fuzzy time series, while otherwise called as time variant fuzzy time series [1].

Definition 3. If the $F(t)$ fuzzy time series is only affected by one lagged $F(t-1)$ fuzzy time series, then the fuzzy relation between $F(t-1)$ and $F(t)$ is expressed as

$$
F(t-1) \longrightarrow F(t)
$$

This is called as a first-order fuzzy time series forecasting model. Then this relation can be expressed as

$$
F(t)=F(t-1) \circ R(t, t-1)
$$

The "o" operator in (2) had been determined as the max-min operator by Song and Chissom $[1,3,4]$.

Definition 4. If $F(t)$ fuzzy time series is affected by the lagged fuzzy time series of $F(t-1), F(t-2), \ldots, F(t-p)$, then the fuzzy relation between $F(t)$ fuzzy time series and $F(t-1), F(t-$ $2), \ldots, F(t-p)$ fuzzy time series may be expressed as

$$
F(t-p), \ldots, F(t-2), F(t-1) \longrightarrow F(t)
$$

and is called the $p$ th order fuzzy time series forecasting model [6]. 


\section{The Proposed Method}

Based on the definition of fuzzy AR(1) given in Definition 3, the definition of the main fuzzy time series to represent the fuzzy $\operatorname{ARMA}(1,1)$ model is expressed as follows.

Definition 5. Let $F(t)$ be a fuzzy time series and let $\varepsilon(t)$ be the fuzzy error series obtained from $F(t)$ fuzzy time series. If $F(t)$ is affected by one lagged $F(t-1)$ and one lagged $\varepsilon(t-1)$ fuzzy time series, then the relationship can be expressed as

$$
F(t-1), \varepsilon(t-1) \longrightarrow F(t) .
$$

This is called as first-order fuzzy autoregressive moving averages (ARMA $(1,1))$ time series forecasting model [18].

In this study, an algorithm has been proposed for solving the ARMA(1,1) fuzzy time series forecasting model defined in (4). In the algorithm proposed, initially the AR(1) fuzzy time series model defined in (1) is estimated. Later on, errors are calculated by taking the differences between the observed values of the times series and the forecasts obtained through the solution of fuzzy AR(1). By using these errors, the fuzzy $\operatorname{ARMA}(1,1)$ model defined in $(4)$ is estimated. The algorithm of the proposed approach is given below.

Algorithm 6. The proposed method's algorithm.

Step 1 (the universe of discourse $(U)$ and subintervals $\left(u_{i}, i=1,2, \ldots b\right)$ are defined). The beginning and the ending points of the universe of discourse for time series are determined. Then $U$ is divided into subintervals according to appropriate interval length. Definition of interval length is up to the researcher. It should not be forgotten that the interval length to be determined affects the number of subintervals. If the smallest value of the time series is taken as $X_{\min }$, the largest value as $X_{\max }$, and two arbitrary values as $D_{1}$ and $D_{2}$, the universal set may be defined as the closed interval of

$$
U=\left[X_{\min }-D_{1}, X_{\max }+D_{2}\right]
$$

$u_{i}$ subintervals determined for $i=1,2, \ldots b$ are the subintervals of the universal set $U$, which is defined as

$$
U=\left\{u_{1}, u_{2}, \ldots, u_{b}\right\}
$$

For example, for $X_{\min }=43$ and $X_{\max }=96$ when $U$ is selected as $[40,100]$ and interval length is selected as 10 , subintervals are specified as $u_{1}=[40,50], u_{2}=[50,60], u_{3}=[60,70]$, $u_{4}=[70,80], u_{5}=[80,90]$, and $u_{6}=[90,100]$.

Step 2. For the time series, fuzzy sets are defined according to the universal set $(U)$ and the divisions of $\left(u_{i}\right)$. These fuzzy sets are expressed as

$$
\begin{array}{r}
A_{i}=\frac{f_{A_{i}}\left(u_{1}\right)}{u_{1}}+\frac{f_{A_{i}}\left(u_{2}\right)}{u_{2}}+\cdots+\frac{f_{A_{i}}\left(u_{b}\right)}{u_{b}}, \\
\text { for } i=1,2, \ldots, b .
\end{array}
$$

For $i=1,2, \ldots b$,

$$
f_{A_{i}}\left(u_{i}\right)= \begin{cases}1, & k=i \\ 0.5, & k=i-1, i+1 \\ 0, & \text { otherwise. }\end{cases}
$$

For example, according to (7) and (8), the fuzzy set of $A_{3}$ can be expressed as $0 / u_{1}+0.5 / u_{2}+1 / u_{3}+0.5 / u_{4}+0 / u_{5}+0 / u_{6}$.

Step 3 (observations are fuzzified). Subintervals $\left(u_{i}\right)$ where each observation occurs are defined. Then the fuzzy set $A_{i}$ where the defined sub-interval has the highest membership value is determined. The fuzzy value of the observation is this $A_{i}$ fuzzy set defined.

Step 4. For the purpose of determining fuzzy relations, fuzzy logic relations are identified and a fuzzy logic group relation table is formed.

For example, where the fuzzy logic relations are as $A_{2} \rightarrow$ $A_{3}, A_{2} \rightarrow A_{3}, A_{2} \rightarrow A_{5}$, according to Chen method [5], the fuzzy logic group relation for $A_{2}$ fuzzy value is as $A_{2} \rightarrow A_{3}, A_{5}$. In the proposed method, this relation occurs to be as $A_{2} \rightarrow A_{3}, A_{3}, A_{5}$. Thus, a little improvement has been realised in the fuzzy AR(1) model of Chen [5] with the proposed method.

Step 5 (fuzzy forecasts are obtained). As $F(t-1)=A_{i}$ and $F(t)=A_{j}, 3$ possible situations regarding forecast obtainment are as follows.

Situation 1. If a relation of $A_{i} \rightarrow A_{j}, \ldots, A_{j}$ is valid on the fuzzy group relation table where $A_{i}$ affects only $a$ pieces of $A_{j}$, then the fuzzy forecast is $A_{j}$. For example, if the group relation for $A_{1}$ is as $A_{1} \rightarrow A_{2}$ that this relation is repeated a few times in the time series, then the fuzzy forecast is specified as $A_{2}$.

Situation 2. If a relation of $A_{i} \rightarrow A_{j}, \ldots, A_{j}, A_{k}, \ldots, A_{k}$, $A_{l}, \ldots, A_{l}$ is valid on the fuzzy group relation table where $A_{i}$ affects $a$ pieces of $A_{j}, b$ pieces $A_{k}$ and $c$ pieces $A_{l}$, then the fuzzy forecast is $A_{j}, \ldots, A_{j}, A_{k}, \ldots, A_{k}, A_{l}, \ldots, A_{l}$, comprising of $a+b+c$ pieces of fuzzy values. For example; if the group relation for $A_{2}$ is as $A_{2} \rightarrow A_{2}, A_{3}, A_{3}, A_{5}, A_{5}, A_{5}$, then the fuzzy forecast is specified as $A_{2}, A_{3}, A_{3}, A_{5}, A_{5}, A_{5}$.

Situation 3. If $A_{i} \rightarrow$ empty on the fuzzy group relation table, the fuzzy forecast occurs to be $A_{i}$. For example, if the group relation for $A_{3}$ is $A_{3} \rightarrow$ empty, then the fuzzy forecast is $A_{3}$.

Step 6 (defuzzification process is executed). In this step, centralisation method is used. When the fuzzy forecast for Situation 1 and Situation 3 defined in Step 5 is $A_{j}$, then the defuzzy forecast should be the middle point of the $u_{j}$ subinterval that has the highest membership value within the fuzzy set $A_{j}$. For Situation 2, the defuzzy forecast is calculated with the weighted average formula below, by using the middle points $\left(m_{j}, m_{k}, \ldots, m_{l}\right)$ of the $u_{j}, u_{k}, \ldots, u_{l}$ intervals that have 
TABLE 1: An example to the fuzzy AR(1) solution of the proposed method.

\begin{tabular}{|c|c|c|c|c|c|c|}
\hline Years & Data & \multicolumn{2}{|c|}{ Fuzzy value } & & Fuzzy forecast & Defuzzy forecast \\
\hline 2001 & 43 & $A_{1}$ & $>$ & & - & - \\
\hline 2002 & 47 & $A_{1}$ & $>$ & $\longrightarrow$ & $A_{1}, A_{1}, A_{1}, A_{2}$ & 47.5 \\
\hline 2003 & 45 & $A_{1}$ & 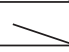 & $\longrightarrow$ & $A_{1}, A_{1}, A_{1}, A_{2}$ & 47.5 \\
\hline \begin{tabular}{|l|}
2004 \\
\end{tabular} & 46 & $A_{1}$ & $>$ & $\longrightarrow$ & $A_{1}, A_{1}, A_{1}, A_{2}$ & 47.5 \\
\hline 2005 & 53 & $\mathrm{~A}_{2}$ & 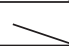 & $\longrightarrow$ & $A_{1}, A_{1}, A_{1}, A_{2}$ & 47.5 \\
\hline 2006 & 65 & $A_{3}$ & $>$ & $\longrightarrow$ & $A_{3}, A_{3}$ & 65 \\
\hline 2007 & 57 & $A_{2}$ & $>$ & $\longrightarrow$ & $A_{2}, A_{2}$ & 55 \\
\hline 2008 & 62 & $A_{3}$ & $>$ & $\longrightarrow$ & $A_{3}, A_{3}$ & 65 \\
\hline 2009 & 51 & $A_{2}$ & & $\longrightarrow$ & $A_{2}, A_{2}$ & 55 \\
\hline
\end{tabular}

the highest membership value of each of the $A_{j}, A_{k}, \ldots, A_{l}$ fuzzy sets. Consider

$$
\widehat{x}(t)=\frac{a \times m_{j}+b \times m_{k}+c \times m_{l}}{a+b+c} .
$$

On an example time series, when solutions are made according to the proposed method from Step 1 to Step 6 as per the determined subintervals of $u_{1}=[40,50], u_{2}=[50,60]$, and $u_{3}=[60,70]$, the solutions displayed in Table 1 are obtained.

Step 7. Errors are calculated by taking the differences between the observed time series values and the defuzzified forecast values obtained in Step 6. Real values of the time series are $x(t)$ and the defuzzified forecast values obtained in Step 6 are $\widehat{x}(t)$; the error series $e(t)$ is calculated as follows:

$$
e(t)=x(t)-\widehat{x}(t) .
$$

Step 8. For the errors, the universe of discourse set is defined as $(V)$ and subintervals are defined as $\left(v_{i}, i=1,2, \ldots b\right)$. The same partition of the universe of discourse processes done in Step 1 is made for the error series.

Step 9. Fuzzy sets based on the universal set $(V)$ and partitions $\left(v_{i}\right)$ are defined for the errors. The fuzzy sets are expressed as

$$
\begin{array}{r}
B_{j}=\frac{f_{B_{j}}\left(v_{1}\right)}{v_{1}}+\frac{f_{B_{j}}\left(v_{2}\right)}{v_{2}}+\cdots+\frac{f_{B_{j}}\left(v_{c}\right)}{v_{c}}, \\
\text { for } j=1,2, \ldots, c .
\end{array}
$$

For $j=1,2, \ldots c$,

$$
f_{B_{j}}\left(v_{j}\right)= \begin{cases}1, & k=j \\ 0.5, & k=j-1, \quad j+1 \\ 0, & \text { otherwise. }\end{cases}
$$

For example, according to (11) and (12), the fuzzy set of $B_{3}$ can be specified as $0 / v_{1}+0.5 / v_{2}+1 / v_{3}+0.5 / v_{4}+0.5 / v_{5}$.

Step 10 (error series $e(t)$ is fuzzified). Subintervals $\left(v_{j}\right)$ for each observation are determined. Then the fuzzy set $B_{j}$ where the determined sub-interval has the highest membership value is defined. The fuzzy value of the observation is this fuzzy set $B_{j}$.
Step 11 (fuzzy relations are determined and fuzzy logic group relation table is formed). The fuzzy value $A_{i}$ of the fuzzy relations time series and the fuzzy value $B_{j}$ of the error series are determined by taking the fuzzy values into consideration together. For the one lagged fuzzy value of the $t$ th observation being $F(t-1)=A_{i}$, one lagged error value being $\varepsilon(t-1)=B_{j}$, and the fuzzy value being $F(t)=A_{k}$, the fuzzy relation given in (4) occurs to be $\left(A_{i}, B_{j}\right) \rightarrow A_{k}$. Thus, the fuzzy values are formed of $\left(A_{i}, B_{j}\right)$ ordered pairs, and a relation in the manner of one lagged time series and error affecting the time series is mentionable. For example, when the fuzzy logic relations are as $\left(A_{2}, B_{3}\right) \rightarrow A_{2},\left(A_{2}, B_{3}\right) \rightarrow A_{2},\left(A_{2}, B_{3}\right) \rightarrow A_{4}$, the fuzzy logic group relation for $\left(A_{2}, B_{3}\right)$ fuzzy value occurs to be $\left(A_{2}, B_{3}\right) \rightarrow A_{2}, A_{2}, A_{4}$.

Step 12 (fuzzy forecasts are obtained). As $F(t-1)=A_{i}$ ve $\varepsilon(t-1)=B_{j}$ and $F(t)=A_{k}, 3$ possible situations regarding forecast obtainment are as follows.

Situation 1. If a relation of $\left(A_{i}, B_{j}\right) \rightarrow A_{k}, \ldots, A_{k}$ is valid on the fuzzy group relation table where $\left(A_{i}, B_{j}\right)$ affects only a pieces of $A_{k}$, then the fuzzy forecast is $A_{k}$. For example, if the group relation for $\left(A_{1}, B_{2}\right)$ is as $\left(A_{1}, B_{2}\right) \rightarrow A_{2}$ that this relation is repeated within a few times in the time series, then the fuzzy forecast is determined as $A_{2}$.

Situation 2. If a relation of $\left(A_{i}, B_{j}\right) \rightarrow A_{k}, \ldots, A_{k}, A_{l}, \ldots, A_{l}$, $A_{m}, \ldots, A_{m}$ is valid on the fuzzy group relation table where $\left(A_{i}, B_{j}\right)$ affects $a$ pieces of $A_{k}, b$ pieces $A_{l}$ and $c$ pieces $A_{m}$, then the fuzzy forecast is $A_{k}, \ldots, A_{k}, A_{l}, \ldots, A_{l}, A_{m}, \ldots, A_{m}$, comprising of $a+b+c$ pieces of fuzzy values. For example, if the group relation for $\left(A_{1}, B_{2}\right)$ is as $\left(A_{1}, B_{2}\right) \rightarrow A_{2}, A_{3}$, $A_{3}, A_{5}, A_{5}, A_{5}$, then the fuzzy forecast is determined as $A_{2}, A_{3}, A_{3}, A_{5}, A_{5}, A_{5}$.

Situation 3. If $\left(A_{i}, B_{j}\right) \rightarrow$ empty on the fuzzy group relation table, the fuzzy forecast occurs to be $A_{i}$. For example, if the group relation for $\left(A_{1}, B_{2}\right)$ is $\left(A_{1}, B_{2}\right) \rightarrow$ empty, then the fuzzy forecast is $A_{1}$.

Step 13 (defuzzification process is made). In this step, centralisation method is used. When the fuzzy forecast for Situation 1 and Situation 3 defined in Step 5 is $A_{j}$, then the defuzzy forecast should be the middle point of the $u_{j}$ sub-interval that has the highest membership value within the fuzzy set 
TABLE 2: An application of the proposed method on an example time series.

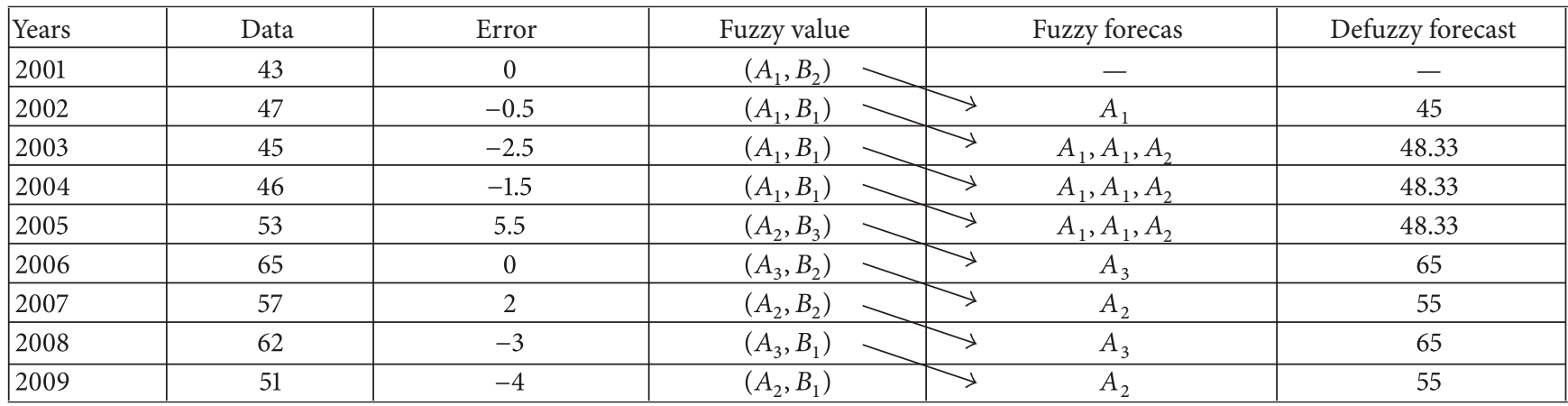

$A_{j}$. For Situation 2, the defuzzy forecast is calculated with the weighted average formula given in (9).

On an example time series, when solutions are made according to the proposed method as per the determined time series subintervals of $u_{1}=[40,50], u_{2}=[50,60]$, and $u_{3}=[60,70]$ and error series subintervals of $v_{1}=[-5,0]$, $v_{2}=[0,5]$, and $v_{3}=[5,10]$, solutions displayed in Table 2 are obtained.

\section{Application}

The performance indicators of the root mean square error (RMSE), mean average percentage error (MAPE), and direction accuracy (DA) values used for comparison of the results obtained are as follows:

$$
\begin{gathered}
\text { RMSE }=\sqrt{\frac{\sum_{t=1}^{n}\left(Y_{t}-\widehat{Y}_{t}\right)^{2}}{n},} \\
\text { MAPE }=\frac{1}{n} \sum_{t=1}^{n}\left|\frac{Y_{t}-\widehat{Y}_{t}}{Y_{t}}\right|, \\
\mathrm{DA}=\frac{1}{n-1} \sum_{t=1}^{n-1} \begin{cases}1, & \left(Y_{t+1}-Y_{t}\right)\left(\widehat{Y}_{t+1}-Y_{t}\right)>0, \\
0, & \text { otherwise. }\end{cases}
\end{gathered}
$$

Data is divided into two within the applications, assigning the first part as training set and the second part as test set obtained through taking the last observations into consideration of which number was predetermined. By looking up the fuzzy relation table obtained for the training set as per the Steps 5 and 12 of the proposed method, the fuzzy forecast of the test set and from there the defuzzy forecasts of the test set are calculated by utilizing Steps 6 and 13 . After, the RMSE, MAPE, and DA values for the test set are calculated. Therefore, the future performances of the methods are determined. As the forecasts with the lowest RMSE value calculated for the test set provide the best result of the used method, the future performances of the forecasts are obtained along with the aid of MAPE and DA values.

Solution of vast majority of some fuzzy forecasting methods in the literature is realised according to the specified number of fuzzy sets, and some are realised according to interval lengths. For the purpose of maintaining consistency during the comparison of forecast performances, the interval length to be used at fuzzification stage is determined as to have the number of fuzzy sets 5 as the lowest and 35 as the highest for each application data and for all methods. Therefore, in case the universal set division is realised in accordance to interval length, the interval lengths to be tried have been specified by calculation with the formula below:

$$
\text { Interval Length }=\frac{\max (\text { data })-\min (\text { data })}{\text { Number of Fuzzy Sets }} .
$$

The operations below have been realised when making solution via the proposed method.

(i) The last $k$ number of data has been specified as test set, aiming to increase the future performances.

(ii) During the fuzzification of time series stage of the proposed method, different time series interval lengths for the division of universal set $U$ have been tried. Data have been solved from Step 1 to Step 6 according to these intervals lengths. And so, a lot of forecasts have been obtained. The test set forecast with the smallest RMSE value among these forecasts has been determined as the best result of the fuzzy AR(1) model.

(iii) The error value of the first observation of data has been assumed as 0 , while the error values of other observations have been calculated with the formula (9) by using the training set and test set forecasts obtained through the best result of the fuzzy AR(1) model. Thus the error series has been obtained.

(iv) Different time series interval lengths and different error series interval lengths have been tried by solving data from Step 1 to Step 13. Among these trials, the test set forecast with the smallest RMSE value has been determined as the best result of the fuzzy $\operatorname{ARMA}(1,1)$ model.

For the purpose of comparing the proposed method with the other fuzzy time series methods in the literature, 2 different data sets comprising of less observations (smaller sample size) and more observations (larger sample size) have been used. One of these data sets is the IMKB time series seen in Figure 1 comprising of 53 observations between 


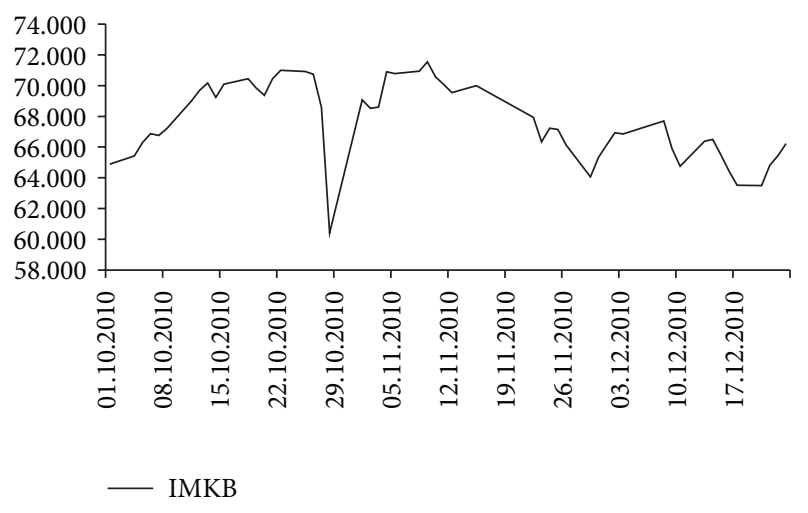

FIgURE 1: Graph of IMKB time series.

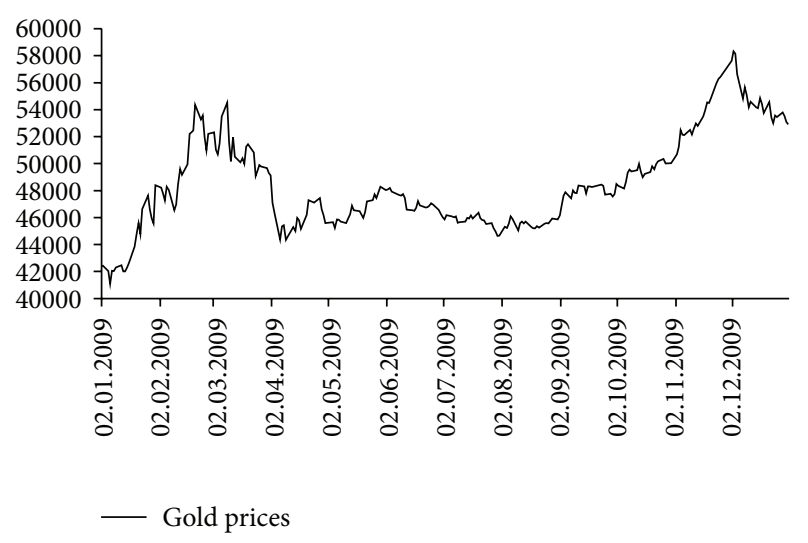

FIGURE 2: Graph of gold prices.

the dates of 01.10.2010 and 23.12.2010. The second data set is the gold prices time series seen in Figure 2 comprising of 248 observations received from Turkish Republic Central Bank (TCMB) website between the dates of 02.01.2009 and 31.12.2009.

In the solution of the IMKB data given in Figure 1 via the methods in the literature by taking the last 7 observations and the last 15 observations as test set, one has the following.

(i) During the fuzzification stage of the Song and Chissom [1] first-order fuzzy time series method, among the 31 different results obtained from increasing the fuzzy set number between 5 and 35 , the test set forecast that has the minimum RMSE value has been determined as the best result of the method from this results.

(ii) For each of the 2nd-, 3rd-, 4th-, and 5th-order models of Chen [5] first-order fuzzy time series forecast method, Chen [6] high order fuzzy time series forecast method, and Aladag et al. [8] high order fuzzy time series forecast method, the RMSE values have been found for different intervals lengths being increased 100 units between 300 and 2300. The test set forecasts that have the minimum RMSE values among these 21 trials have been determined as the best results of the methods. (iii) By using the optimal interval lengths calculated with the distribution-based approach of Huarng [11] and the average-based approaches, solution has been executed as per the first-order fuzzy time series forecast method of Chen [5]. Thus, the best results of the test set from the distribution based approach and the average-based approaches have been obtained via a single trial.

(iv) In the application of the ratio-based approach of Huarng and $\mathrm{Yu}$ [13], alpha parameter has been taken as 0.50 , obtaining the best result for the test set of the method in one trial.

In the solution of the IMKB time series seen in Figure 1 via the proposed method by taking the number of test sets 7 and 15 , one has the following.

(i) The division of universal set $U$ have been taken different values as increasing the interval length between 300 and 2300 by 100 units and different forecasts have been obtained by solving from Step 1 to Step 6. The test set forecast with the smallest RMSE value among these forecasts has been determined as the best result of the fuzzy AR(1) model. The best fuzzy AR(1) results have been obtained when the interval length is 300 for 7 as the number of test sets and when the interval length is 900 for 15 as the number of test sets.

(ii) The error value of the first observation of data has been assumed as 0 , while the error values of other observations have been calculated via the formula (9) by utilising data and forecasts obtained through the best result of the fuzzy AR(1) model. Thus the error series has been obtained for 53 observations.

(iii) Different trials have been made by increasing the interval length between 300 and 2300 by 100 units for the time series and by increasing the interval length between 300 and 2100 by 100 units for the error series by solving from Step 1 to Step 13. Among these trials, the test set forecast with the smallest RMSE value has been determined as the best result of the fuzzy ARMA $(1,1)$ model.

During the application of the proposed method and the methods in the literature on IMKB time series, the parameters with which the forecasts with the best test set performance for 7 and 15 numbers of test sets occurred to be

(i) for the application of Song and Chissom [1] method, when the number of fuzzy sets is 9 for 7 and 20 for 15 ,

(ii) for the application of Chen [5] method, when the interval length is 300 for 7 and 900 for 15,

(iii) for the application of distribution-based Huarng [11] approach, when the interval length is 1000 , and for the application of average based approach, when the interval length is 200 ,

(iv) for the application of ratio-based Huarng and Yu [13] approach, when the sample percentile alpha $=0.5$, 
TABLE 3: The best results obtained for 7-observation test set of IMKB data.

\begin{tabular}{|c|c|c|c|c|c|c|c|c|c|}
\hline Date & Test set & $\begin{array}{c}\text { Song and } \\
\text { Chissom [1] }\end{array}$ & Chen [5] & Chen [6] & $\begin{array}{l}\text { Huarng [11] } \\
\text { distribution- } \\
\text { based } \\
\text { method } \\
\end{array}$ & $\begin{array}{c}\text { Huarng [11] } \\
\text { average-based } \\
\text { method }\end{array}$ & $\begin{array}{c}\text { Huarng and Yu } \\
{[13]} \\
\text { rational-based } \\
\text { method } \\
\end{array}$ & Aladag et al. [8] & $\begin{array}{l}\text { Proposed } \\
\text { method }^{*}\end{array}$ \\
\hline 15.12.2010 & 65499 & 65356 & 66550 & 65900.0 & 67400 & 66500 & 66784.7 & 67300 & 66266.7 \\
\hline 16.12.2010 & 64429 & 65356 & 66250 & 65900.0 & 65400 & 66300 & 66178.0 & 64900 & 63700.0 \\
\hline 17.12 .2010 & 63524 & 65975 & 64450 & 64800.0 & 65900 & 64500 & 65878.7 & 64900 & 63700.0 \\
\hline 20.12.2010 & 63502 & 64737 & 63550 & 64066.7 & 64900 & 63500 & 63514.3 & 64300 & 63700.0 \\
\hline 21.12.2010 & 64820 & 64737 & 63550 & 63700.0 & 64900 & 63500 & 63514.3 & 63700 & 65900.0 \\
\hline 22.12 .2010 & 65440 & 65975 & 65800 & 64800.0 & 65900 & 65500 & 65878.7 & 65500 & 65900.0 \\
\hline \multirow[t]{4}{*}{ 23.12.2010 } & 66219 & 65356 & 66250 & 65900.0 & 65400 & 66300 & 66178.0 & 66700 & 66266.7 \\
\hline & RMSE & 1161.91 & 1001.70 & 928.70 & 1365.14 & 1014.73 & 1317.77 & 1034.06 & 606.07 \\
\hline & MAPE & 0.01387 & 0.01217 & 0.01283 & 0.01773 & 0.01175 & 0.01593 & 0.01350 & 0.00762 \\
\hline & DA & 0.50000 & 0.50000 & 0.33333 & 0.50000 & 0.50000 & 0.66667 & 0.66667 & 0.83333 \\
\hline
\end{tabular}

${ }^{*}$ The best situation.

(v) for the application of Chen [6] method, when the interval length is 2200 in 3rd-order model for 7 and 1400 in 2nd-order model for 15,

(vi) For the application of Aladag et al. [8] method, when the interval length is 600 on 2nd-degree model and unit number of artificial neural network hidden layers is 5 for 7 , and when the interval length is 1500 on 2 nddegree model and unit number of artificial neural network hidden layers is 6 for 15 ,

(vii) For the application of the proposed fuzzy ARMA(1,1) method, when the interval length of time series is 2200 and the interval length of error series is 1400 for 7 , and when the interval length of time series is 1400 and the interval length of error series is 400 for 15 .

Best forecasts and forecast performances of all methods in result of IMKB time series solution for 7 observation test set are summarised in Table 3.

When Table 3 is analyzed, it is seen in result of the solution of IMKB time series for 7 observation test set that the proposed method produced the best forecasting performance with a minimum RMSE value of 606.07 , minimum MAPE value of $0.762 \%$, and maximum direction accuracy of $83.33 \%$. The graphs of the last 7 observations of IMKB time series along with the 7-observation test set forecasts obtained with the proposed method are shown together in Figure 3.

Best forecasts and forecast performances of all methods in result of IMKB time series solution for 15-observation test set are summarised in Table 4.

When Table 4 is analyzed, it is seen that the proposed method produced the best forecasting performance with a minimum RMSE value of 865.28 , minimum MAPE value of $1.029 \%$, and maximum direction accuracy of $71.43 \%$ in result of the solution of IMKB time series for 15-observation test set. The graphs of the last 15 observations of IMKB time series along with the 15-observation test set forecasts obtained with the proposed method are shown together in Figure 4.

In result of the solutions of IMKB time series, it has been observed that the proposed method significantly increased

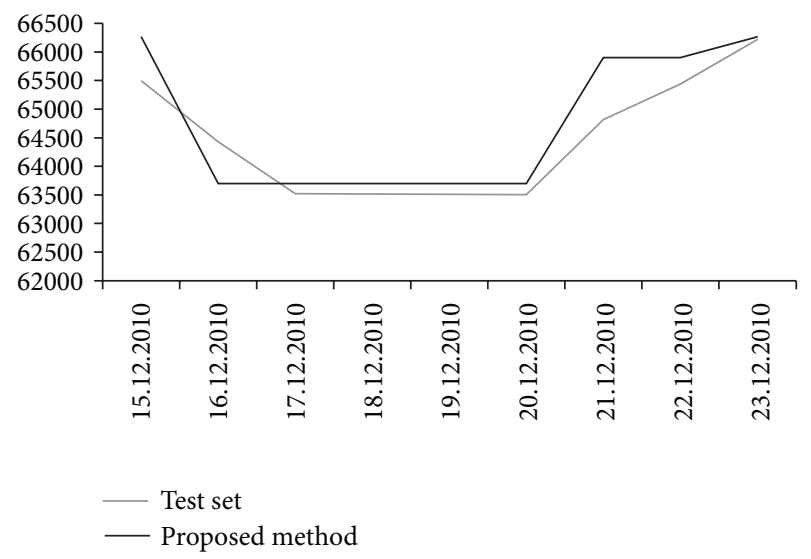

FIGURE 3: The graphs of the 7-observation test set of IMKB data and the forecasts of the test set obtained with the proposed method.

the future forecasting performance compared to other methods. Also in the graphs within Figures 3 and 4, the results of the proposed method are seen to be considerably similar to the test set values.

In the solution of the gold prices data given in Figure 2 via the methods in the literature by taking the last 30 observations and the last 45 observations as test set, one has the following.

(i) Gold prices solution of Song and Chissom [1], Huarng [11], and Huarng and Yu [13] methods has been conducted just as previously done on the abovementioned IMKB time series.

(ii) For each of the 2nd-, 3rd-, 4th-, and 5th-order models of Chen [5] first-order fuzzy time series forecast method, Chen [6] high-order fuzzy time series forecast method, and Aladag et al. [8] high order fuzzy time series forecast method, the RMSE values have been found for different lengths being increased 100 units between 500 and 3500 . The test set forecasts 
TABLE 4: The best results obtained for 15-observation test set of IMKB data.

\begin{tabular}{|c|c|c|c|c|c|c|c|c|c|}
\hline Date & Test set & $\begin{array}{l}\text { Song and } \\
\text { Chissom [1] }\end{array}$ & Chen [5] & Chen [6] & $\begin{array}{l}\text { Huarng [11] } \\
\text { distribution- } \\
\text { based } \\
\text { method } \\
\end{array}$ & $\begin{array}{c}\text { Huarng [11] } \\
\text { average-based } \\
\text { method }\end{array}$ & $\begin{array}{c}\text { Huarng and Yu } \\
{[13]} \\
\text { rational-based } \\
\text { method } \\
\end{array}$ & Aladag et al. [8] & $\begin{array}{l}\text { Proposed } \\
\text { method }^{*}\end{array}$ \\
\hline 01.12 .2010 & 66156 & 65695.5 & 66250 & 64833.3 & 65900.0 & 65300 & 66328.8 & 65650 & 66000 \\
\hline 02.12 .2010 & 66939 & 66438.2 & 65800 & 66700.0 & 65566.7 & 64100 & 66164.2 & 67150 & 67633 \\
\hline 03.12 .2010 & 66860 & 67088.0 & 67450 & 66700.0 & 67233.3 & 66700 & 67143.8 & 67150 & 66700 \\
\hline 08.12 .2010 & 67705 & 67088.0 & 67450 & 66700.0 & 67233.3 & 66700 & 67143.8 & 67150 & 66700 \\
\hline 09.12 .2010 & 65914 & 66252.5 & 66250 & 67633.3 & 65900.0 & 67700 & 66328.8 & 67150 & 68100 \\
\hline 10.12 .2010 & 64759 & 65695.5 & 65800 & 66233.3 & 65566.7 & 65900 & 65791.4 & 64150 & 65300 \\
\hline 13.12.2010 & 66380 & 65695.5 & 65350 & 66700.0 & 65900.0 & 64700 & 65258.3 & 65650 & 65300 \\
\hline 14.12.2010 & 66510 & 66438.2 & 65800 & 66700.0 & 65566.7 & 67100 & 66164.2 & 65650 & 66700 \\
\hline 15.12 .2010 & 65499 & 66438.2 & 65800 & 66700.0 & 67233.3 & 66500 & 66164.2 & 67150 & 66700 \\
\hline 16.12 .2010 & 64429 & 65695.5 & 66250 & 65766.7 & 65566.7 & 66300 & 66328.8 & 64150 & 65300 \\
\hline 17.12 .2010 & 63524 & 65695.5 & 65350 & 64366.7 & 65900.0 & 64500 & 65258.3 & 65650 & 63900 \\
\hline 20.12.2010 & 63502 & 65138.5 & 63550 & 63900.0 & 64900.0 & 63500 & 63684.8 & 65650 & 63900 \\
\hline 21.12.2010 & 64820 & 65138.5 & 63550 & 63900.0 & 64900.0 & 63500 & 63684.8 & 65650 & 63900 \\
\hline 22.12 .2010 & 65440 & 65695.5 & 65350 & 64833.3 & 65900.0 & 65500 & 65258.3 & 65650 & 65300 \\
\hline \multirow[t]{4}{*}{23.12 .2010} & 66219 & 65695.5 & 66250 & 66700.0 & 65566.7 & 66300 & 66328.8 & 65650 & 66000 \\
\hline & RMSE & 919.47 & 925.42 & 954.17 & 1052.90 & 1283.18 & 896.96 & 1060.12 & 865.28 \\
\hline & MAPE & 0.01124 & 0.01081 & 0.01245 & 0.01285 & 0.01558 & 0.01085 & 0.01312 & 0.01029 \\
\hline & DA & 0.71429 & 0.57143 & 0.64286 & 0.50000 & 0.57143 & 0.64286 & 0.64286 & 0.71429 \\
\hline
\end{tabular}

${ }^{*}$ The best result.

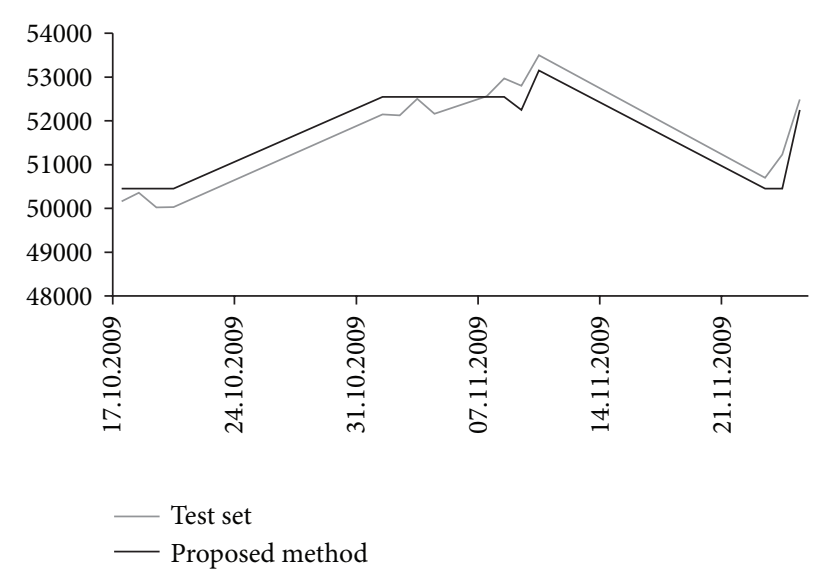

FIGURE 4: The graphs of the 15-observation test set of IMKB data and forecasts of the test set obtained with the proposed method.

that have the minimum RMSE values among these 31 trials have been determined as the best results of the methods.

In the solution of the gold prices data given in Figure 2 via the proposed method by taking the last 30 observations and the last 45 observations as test set, one has the following.

(i) During the fuzzification of time series of the proposed method, interval lengths of $U$ have been tried as increasing the interval length between 500 and 3500 by 100 units by solving from Steps 1 and 6 . The test set forecast with the smallest RMSE value among these forecasts has been determined as the best result of the fuzzy AR(1) model.

(ii) The error series have been obtained via the formula (9) for 248 observations with the same calculation made previously in the application of IMKB data.

(iii) Different trials have been made by increasing the interval length between 500 and 3500 by 100 units for the time series and by increasing the interval length between 100 and 1100 by 50 units for the error series by solving from Step 1 to Step 13. Among these trials, the test set forecast with the smallest RMSE value has been determined as the best result of the fuzzy $\operatorname{ARMA}(1,1)$ model.

During the application of the proposed method and the methods in the literature on gold prices time series, the parameters with which the forecasts with the best test set performance for 30 and 45 test sets occurred to be the following:

(i) for the application of Song and Chissom [1] method, when the number of fuzzy sets is 10 for both 30 and 45 test sets,

(ii) for the application of Chen [5] method, when the interval length is 600 for 30 and 1700 for 45 ,

(iii) for the application of distribution-based Huarng approach [11], when the interval length is 400 , and for the application of average based approach, when the interval length is 200 , 
TABLE 5: The best results obtained for 30-observation test set of gold prices.

\begin{tabular}{|c|c|c|c|c|c|c|c|c|c|}
\hline Date & Test set & $\begin{array}{l}\text { Song and } \\
\text { Chissom [1] }\end{array}$ & Chen [5] & Chen [6] & $\begin{array}{c}\text { Huarng [11] } \\
\text { distribution- } \\
\text { based } \\
\text { method }\end{array}$ & $\begin{array}{c}\text { Huarng [11] } \\
\text { average-based } \\
\text { method }\end{array}$ & $\begin{array}{c}\text { Huarng and Yu } \\
{[13]} \\
\text { rational-based } \\
\text { method }\end{array}$ & Aladag et al. [8] & $\begin{array}{l}\text { Proposed } \\
\text { method }^{*}\end{array}$ \\
\hline 17.11.2009 & 53935 & 53157 & 53300 & 53000.0 & 53200 & 53200 & 53356.4 & 53300 & 53400 \\
\hline 18.11.2009 & 54550 & 53157 & 53900 & 53666.7 & 54000 & 53900 & 53894.0 & 53900 & 54200 \\
\hline 19.11.2009 & 54495 & 53157 & 52400 & 54066.7 & 52400 & 51500 & 51715.7 & 54500 & 54200 \\
\hline 20.11.2009 & 54830 & 53157 & 52400 & 54200.0 & 52400 & 51500 & 51715.7 & 53900 & 54200 \\
\hline 23.11.2009 & 55950 & 53157 & 55100 & 54600.0 & 54800 & 54900 & 55017.3 & 54500 & 55000 \\
\hline 24.11.2009 & 56285 & 52294 & 55700 & 55266.7 & 56000 & 55900 & 55779.2 & 55100 & 55800 \\
\hline 25.11.2009 & 56430 & 52294 & 56300 & 56066.7 & 56400 & 56300 & 56164.1 & 55700 & 56600 \\
\hline 01.12 .2009 & 57635 & 52294 & 56300 & 56466.7 & 56400 & 56500 & 56551.6 & 55100 & 56600 \\
\hline 02.12.2009 & 58330 & 53157 & 57500 & 57000.0 & 57600 & 57700 & 57730.3 & 55700 & 57400 \\
\hline 03.12.2009 & 58150 & 53157 & 58100 & 57666.7 & 58400 & 58300 & 58529.8 & 56300 & 58200 \\
\hline 04.12 .2009 & 56630 & 53157 & 58100 & 58066.7 & 58000 & 58100 & 58128.7 & 56300 & 58200 \\
\hline 07.12 .2009 & 54820 & 53157 & 56900 & 57400.0 & 56800 & 56700 & 56551.6 & 55100 & 56600 \\
\hline 08.12.2009 & 55660 & 53157 & 55100 & 56066.7 & 54800 & 54900 & 51715.7 & 55100 & 55000 \\
\hline 09.12.2009 & 55110 & 52294 & 55700 & 55666.7 & 55600 & 55700 & 55779.2 & 55100 & 55800 \\
\hline 10.12.2009 & 54180 & 52294 & 55100 & 55266.7 & 55200 & 55100 & 55017.3 & 54500 & 55000 \\
\hline 11.12 .2009 & 54580 & 53157 & 53900 & 54733.3 & 54000 & 54100 & 53157.9 & 53900 & 54200 \\
\hline 14.12.2009 & 54190 & 53157 & 52400 & 54333.3 & 52400 & 51500 & 51715.7 & 54500 & 54200 \\
\hline 15.12.2009 & 54120 & 53157 & 53900 & 54200.0 & 54000 & 54100 & 53157.9 & 53300 & 54200 \\
\hline 16.12.2009 & 54855 & 53157 & 53900 & 54200.0 & 54000 & 54100 & 53157.9 & 53900 & 54200 \\
\hline 17.12.2009 & 54430 & 53157 & 55100 & 54600.0 & 54800 & 54900 & 55017.3 & 54500 & 55000 \\
\hline 18.12.2009 & 53750 & 53157 & 52400 & 54466.7 & 52400 & 51500 & 53157.9 & 54500 & 54200 \\
\hline 21.12.2009 & 54570 & 53157 & 53900 & 53933.3 & 53200 & 53700 & 53894.0 & 53300 & 53400 \\
\hline 22.12.2009 & 53400 & 53157 & 52400 & 53933.3 & 52400 & 51500 & 51715.7 & 54500 & 54200 \\
\hline 23.12.2009 & 52990 & 53157 & 53300 & 53666.7 & 53200 & 53200 & 53356.4 & 53300 & 53400 \\
\hline 24.12.2009 & 53575 & 52294 & 53150 & 53133.3 & 53200 & 53200 & 53524.7 & 52700 & 53400 \\
\hline 25.12.2009 & 53450 & 53157 & 53300 & 53133.3 & 53200 & 53200 & 53356.4 & 53300 & 53400 \\
\hline 28.12.2009 & 53795 & 53157 & 53300 & 53266.7 & 53200 & 53200 & 53356.4 & 53300 & 53400 \\
\hline 29.12.2009 & 53515 & 53157 & 53900 & 53400.0 & 53200 & 53700 & 53894.0 & 53900 & 53400 \\
\hline 30.12 .2009 & 53095 & 53157 & 53300 & 53400.0 & 53200 & 53200 & 53356.4 & 52700 & 53400 \\
\hline \multirow[t]{4}{*}{31.12 .2009} & 52920 & 52294 & 53300 & 53400.0 & 53600 & 53100 & 53524.7 & 53300 & 53400 \\
\hline & RMSE & 2410.96 & 1031.12 & 857.34 & 1045.23 & 1288.80 & 1412.66 & 1003.50 & 707.71 \\
\hline & MAPE & 0.03339 & 0.01512 & 0.01245 & 0.01530 & 0.01713 & 0.01935 & 0.01382 & 0.01028 \\
\hline & DA & 0.55172 & 0.55172 & 0.51724 & 0.55172 & 0.62069 & 0.55172 & 0.48276 & 0.62069 \\
\hline
\end{tabular}

${ }^{*}$ The best result.

(iv) for the application of ratio-based Huarng and Yu [13] approach, when the sample percentile alpha $=0.5$,

(v) for the application of Chen method [6], when the interval length is 1900 in 5th order model for 30 and 800 in 3rd-order model for 45 ,

(vi) for the application of Aladag et al. [8], when the interval length is 600 on 5th-degree model and unit number of artificial neural network hidden layers is 5 for 30 , and when the interval length is 800 on $3 \mathrm{rd}$ degree model and unit number of artificial neural network hidden layers is 4 for 45 , (vii) for the application of the proposed fuzzy $\operatorname{ARMA}(1,1)$ method, when the interval length of time series is 800 and the interval length of error series is 2500 for 30 , and when the interval length of time series is 900 and the interval length of error series is 1000 for 45 .

Best forecasts and forecast performances of all methods in result of gold prices time series solution for 30-observation test set are summarised in Table 5.

When Table 5 is observed, it is seen in result of the solution of gold prices time series for 30 observation test set 
TABLE 6: The best results obtained for 45-observation test set of gold prices.

\begin{tabular}{|c|c|c|c|c|c|c|c|c|c|}
\hline Date & Test set & $\begin{array}{c}\text { Song and } \\
\text { Chissom [1] }\end{array}$ & Chen [5] & Chen [6] & $\begin{array}{l}\text { Huarng [11] } \\
\text { distribution- } \\
\text { based } \\
\text { method }\end{array}$ & $\begin{array}{c}\text { Huarng [11] } \\
\text { average-based } \\
\text { method }\end{array}$ & $\begin{array}{c}\text { Huarng and Yu } \\
{[13]} \\
\text { rational-based } \\
\text { method }\end{array}$ & Aladag et al. [8] & $\begin{array}{l}\text { Proposed } \\
\text { method* }^{*}\end{array}$ \\
\hline 17.10 .2009 & 50162 & 50568 & 50350 & 49933.3 & 50800.0 & 50420.0 & 50829.1 & 50200 & 50450 \\
\hline 18.10.2009 & 50355 & 50568 & 50350 & 50066.7 & 50800.0 & 51100.0 & 50829.1 & 50200 & 50450 \\
\hline 19.10.2009 & 50020 & 50568 & 50350 & 50120.0 & 50000.0 & 49900.0 & 50051.5 & 50200 & 50450 \\
\hline 20.10.2009 & 950030 & 50568 & 50350 & 51000.0 & 50800.0 & 51100.0 & 50829.1 & 50200 & 50450 \\
\hline 23.11.2009 & 50700 & 50568 & 50350 & 51000.0 & 50800.0 & 51100.0 & 50829.1 & 50200 & 50450 \\
\hline 24.11.2009 & 51230 & 50568 & 50350 & 51800.0 & 51066.7 & 51500.0 & 50824.1 & 51000 & 50450 \\
\hline 25.11.2009 & 52490 & 50568 & 52050 & 50866.7 & 51200.0 & 51500.0 & 51128.5 & 51000 & 52250 \\
\hline 01.11.2009 & 52150 & 52294 & 52050 & 51800.0 & 52666.7 & 54300.0 & 54499.6 & 52600 & 52550 \\
\hline 02.11.2009 & 52125 & 52294 & 52050 & 51933.3 & 50600.0 & 52100.0 & 51916.0 & 51800 & 52550 \\
\hline 03.11.2009 & 52500 & 52294 & 52050 & 51933.3 & 50600.0 & 52100.0 & 51916.0 & 51800 & 52550 \\
\hline 04.11.2009 & 52165 & 52294 & 52050 & 52200.0 & 52666.7 & 54300.0 & 54499.6 & 52600 & 52550 \\
\hline 07.11.2009 & 52560 & 52294 & 52050 & 52066.7 & 50600.0 & 52100.0 & 51916.0 & 51800 & 52550 \\
\hline 08.11.2009 & 52972 & 52294 & 52050 & 52333.3 & 52666.7 & 54300.0 & 54499.6 & 52600 & 52550 \\
\hline 09.11.2009 & 52800 & 52294 & 52900 & 52466.7 & 52800.0 & 52900.0 & 52867.3 & 52600 & 52250 \\
\hline 10.11.2009 & 53500 & 52294 & 52050 & 54200.0 & 52800.0 & 52900.0 & 52867.3 & 52600 & 53150 \\
\hline 17.11.2009 & 53935 & 53157 & 52900 & 53000.0 & 53200.0 & 53200.0 & 53205.5 & 53400 & 54950 \\
\hline 18.11.2009 & 54550 & 53157 & 52900 & 53666.7 & 54000.0 & 53900.0 & 53840.7 & 53400 & 54050 \\
\hline 19.11.2009 & 54495 & 53157 & 52900 & 54066.7 & 52400.0 & 51500.0 & 52393.3 & 54200 & 54950 \\
\hline 20.11.2009 & 54830 & 53157 & 52900 & 54200.0 & 52400.0 & 51500.0 & 52393.3 & 54200 & 54050 \\
\hline 23.11.2009 & 55950 & 53157 & 55450 & 54600.0 & 54800.0 & 54900.0 & 54832.0 & 54200 & 54950 \\
\hline 24.11.2009 & 56285 & 52294 & 55450 & 55266.7 & 56000.0 & 55900.0 & 55841.6 & 54200 & 55850 \\
\hline 25.11.2009 & 56430 & 52294 & 55450 & 56066.7 & 56400.0 & 56300.0 & 56182.2 & 55000 & 55850 \\
\hline 01.12.2009 & 57635 & 52294 & 57150 & 56466.7 & 56400.0 & 56500.0 & 56524.9 & 55000 & 56750 \\
\hline 02.12.2009 & 58330 & 53157 & 57150 & 57000.0 & 57600.0 & 57700.0 & 57565.6 & 55000 & 57650 \\
\hline 03.12.2009 & 58150 & 53157 & 58850 & 57666.7 & 58400.0 & 58300.0 & 58270.1 & 55000 & 58550 \\
\hline 04.12.2009 & 956630 & 53157 & 58850 & 58066.7 & 58000.0 & 58100.0 & 58270.1 & 55800 & 58550 \\
\hline 07.12.2009 & 54820 & 53157 & 57150 & 57400.0 & 56800.0 & 56700.0 & 56524.9 & 55800 & 56750 \\
\hline 08.12.2009 & 95660 & 53157 & 55450 & 56066.7 & 54800.0 & 54900.0 & 54832.0 & 55000 & 54950 \\
\hline 09.12.2009 & 95110 & 52294 & 55450 & 55666.7 & 55600.0 & 55700.0 & 55503.0 & 54200 & 55850 \\
\hline 10.12.2009 & 54180 & 52294 & 55450 & 55266.7 & 55200.0 & 55100.0 & 55166.5 & 54200 & 54950 \\
\hline 11.12 .2009 & 54580 & 53157 & 52900 & 54733.3 & 54000.0 & 54100.0 & 54169.1 & 54200 & 54050 \\
\hline 14.12.2009 & 54190 & 53157 & 52900 & 54333.3 & 52400.0 & 51500.0 & 52393.3 & 54200 & 54950 \\
\hline 15.12.2009 & 54120 & 53157 & 52900 & 54200.0 & 54000.0 & 54100.0 & 54169.1 & 54200 & 54050 \\
\hline 16.12 .2009 & 54855 & 53157 & 52900 & 54200.0 & 54000.0 & 54100.0 & 54169.1 & 54200 & 54050 \\
\hline 17.12 .2009 & 54430 & 53157 & 55450 & 54600.0 & 54800.0 & 54900.0 & 54832.0 & 54200 & 54950 \\
\hline 18.12.2009 & 53750 & 53157 & 52900 & 54466.7 & 52400.0 & 51500.0 & 52393.3 & 54200 & 54050 \\
\hline 21.12.2009 & 54570 & 53157 & 52900 & 53933.3 & 53200.0 & 53700.0 & 53840.7 & 53400 & 54050 \\
\hline 22.12.2009 & 53400 & 53157 & 52900 & 53933.3 & 52400.0 & 51500.0 & 52393.3 & 53400 & 54950 \\
\hline 23.12.2009 & 52990 & 53157 & 52900 & 53666.7 & 53200.0 & 53200.0 & 53205.5 & 53400 & 53150 \\
\hline 24.12.2009 & 9 53575 & 52294 & 52900 & 53133.3 & 52800.0 & 52900.0 & 52867.3 & 52600 & 53150 \\
\hline 25.12.2009 & 53450 & 53157 & 52900 & 53133.3 & 53200.0 & 53200.0 & 53205.5 & 53400 & 52250 \\
\hline 28.12.2009 & 53795 & 53157 & 52900 & 53266.7 & 53200.0 & 53200.0 & 53205.5 & 53400 & 53150 \\
\hline 29.12.2009 & 53515 & 53157 & 52900 & 53400.0 & 53200.0 & 53700.0 & 53840.7 & 53400 & 54050 \\
\hline 30.12 .2009 & 93095 & 53157 & 52900 & 53400.0 & 53200.0 & 53200.0 & 53205.5 & 53400 & 53150 \\
\hline \multirow[t]{4}{*}{31.12 .2009} & 52920 & 52294 & 52900 & 53400.0 & 53600.0 & 53100.0 & 53514.3 & 53400 & 53150 \\
\hline & RMSE & 2009.32 & 1028.39 & 787.71 & 1022.13 & 1200.24 & 1041.74 & 1068.71 & 719.69 \\
\hline & MAPE & 0.02556 & 0.01499 & 0.01146 & 0.01499 & 0.01628 & 0.01517 & 0.01328 & 0.01072 \\
\hline & DA & 0.54545 & 0.52273 & 0.54545 & 0.52273 & 0.61364 & 0.59091 & 0.54545 & 0.50000 \\
\hline
\end{tabular}

\footnotetext{
${ }^{*}$ The best result.
} 


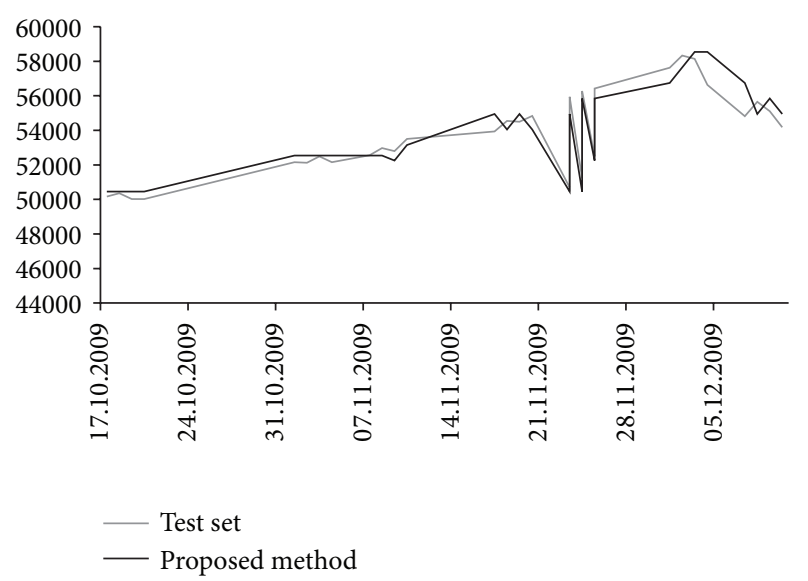

Figure 5: The graphs of the 30-observation test set of gold prices and forecasts of the test set obtained with the proposed method.

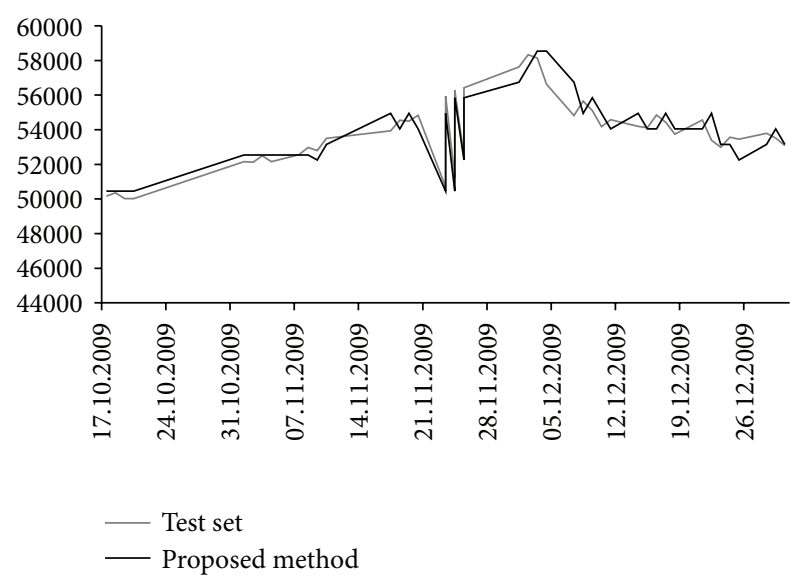

FIGURE 6: The graphs of the 45-observation test set of gold prices and forecasts of the test set obtained with the proposed method.

that the proposed method produced the best forecasting performance with a minimum RMSE value of 707.71, minimum MAPE value of $1.028 \%$, and maximum direction accuracy of $62.07 \%$. The graphs of the last 30 observations of gold prices time series along with the 30 -observation test set forecasts obtained with the proposed method are shown together in Figure 5.

Best forecasts and forecast performances of all methods in result of gold prices time series solution for 45-observation test set are summarised in Table 6. Furthermore, the graphs of the last 45 observations of gold prices time series along with the 45-observation test set forecasts obtained with the proposed method are shown together in Figure 6.

When Table 6 is evaluated, it is seen in result of the solution of gold prices time series for 45 observation test set that the proposed method produced the best forecasting performance with a minimum RMSE value of 719.69, minimum MAPE value of $1.072 \%$.

In result of the solutions of gold prices time series, it has been observed that the proposed method significantly increased the future forecasting performance compared to
TABLE 7: $R / S$ test results.

\begin{tabular}{lcc}
\hline Data & $R / S$ statistics & $P<0.01$ \\
\hline IMKB & 1.6523 & No \\
Gold price & 1.9560 & No \\
\hline
\end{tabular}

other methods. Also in the graphs within Figures 5 and 6 , the results of the proposed method are seen to be considerably similar to the test set values.

\section{Discussion and Conclusion}

MA variables are not included in the fuzzy time series forecast models proposed in the literature whereas real life time series are also influenced from MA variables in addition to AR variables. Therefore, redefining fuzzy times series methods as models including also MA variables are a more realistic act. In this study, a solution algorithm for a new first-order fuzzy ARMA(1,1) time series forecast model containing not only AR but also MA variables is proposed based on group relation tables. The method proposed is a basic algorithm similar to Chen [5] approach, aiming at eliminating the model specification error formed due to the exclusion of MA variables. In conclusion of the applications, it has been observed that the proposed method has higher forecasting performance than many of the fuzzy time series forecasting methods commonly used in the literature. It is an important finding that although the proposed method is a basic method based on group relation tables, it may have a higher forecasting performance even than the high order fuzzy time series methods based on artificial neural networks. Therefore, it is obvious that forecasting performance is going to increase significantly when fuzzy ARMA models are developed where fuzzy relations are specified with artificial neural networks and artificial intelligence methods or where membership values are used for specification of fuzzy relations. Thus, the proposed method may be provided with a more systematic structure and higher forecasting performance with improvements that may be done on various stages of the method during future studies. Moreover, there is no linear model assumption in the proposed fuzzy time series method. Thus, the proposed method and other fuzzy time series methods can be applied to nonlinear time series. In the application, proposed method is applied to short range dependent time series. In the future studies, it will be researched about the performance of the proposed method for long range dependent time series.

\section{Appendix}

The $R / S$ test was applied to two time series which are used in the application. $R / S$ test was applied by using "FinMetrics module of S-PLUS package program". The obtained results are shown in Table 7. It is obtained that both of time series have short range dependence. 


\section{References}

[1] Q. Song and B. S. Chissom, "Fuzzy time series and its models," Fuzzy Sets and Systems, vol. 54, no. 3, pp. 269-277, 1993.

[2] L. A. Zadeh, "Fuzzy sets," Information and Computation, vol. 8, pp. 338-353, 1965.

[3] Q. Song and B. S. Chissom, "Forecasting enrollments with fuzzy time series. Part I," Fuzzy Sets and Systems, vol. 54, pp. 1-10, 1993.

[4] Q. Song and B. S. Chissom, "Forecasting enrollments with fuzzy time series. Part II," Fuzzy Sets and Systems, vol. 62, no. 1, pp. 1-8, 1994.

[5] S.-M. Chen, "Forecasting enrollments based on fuzzy time series," Fuzzy Sets and Systems, vol. 81, no. 3, pp. 311-319, 1996.

[6] S.-M. Chen, "Forecasting enrollments based on high-order fuzzy time series," Cybernetics and Systems, vol. 33, no. 1, pp. 1$16,2002$.

[7] K. Huarng and H.-K. Yu, "The application of neural networks to forecast fuzzy time series," Physica A, vol. 363, no. 2, pp. 481-491, 2006.

[8] C. H. Aladag, M. A. Basaran, E. Egrioglu, U. Yolcu, and V. R. Uslu, "Forecasting in high order fuzzy times series by using neural networks to define fuzzy relations," Expert Systems with Applications, vol. 36, no. 3, pp. 4228-4231, 2009.

[9] T. H.-K. Yu and K.-H. Huarng, "A neural network-based fuzzy time series model to improve forecasting," Expert Systems with Applications, vol. 37, no. 4, pp. 3366-3372, 2010.

[10] U. Yolcu, C. H. Aladag, E. Egrioglu, and V. R. Uslu, “Time series forecasting with a novel fuzzy time series approach: an example for Istanbul stock market," Journal of Statistical Computation and Simulation, vol. 83, no. 4, pp. 599-612, 2013.

[11] K. Huarng, "Effective lengths of intervals to improve forecasting in fuzzy time series," Fuzzy Sets and Systems, vol. 123, no. 3, pp. 387-394, 2001.

[12] E. Egrioglu, C. H. Aladag, U. Yolcu, V. R. Uslu, and M. A. Basaran, "Finding an optimal interval length in high order fuzzy time series," Expert Systems with Applications, vol. 37, no. 7, pp. 5052-5055, 2010.

[13] K. Huarng and T. H.-K. Yu, "Ratio-based lengths of intervals to improve fuzzy time series forecasting," IEEE Transactions on Systems, Man, and Cybernetics B, vol. 36, no. 2, pp. 328-340, 2006.

[14] U. Yolcu, E. Egrioglu, V. R. Uslu, M. A. Basaran, and C. H. Aladag, "A new approach for determining the length of intervals for fuzzy time series," Applied Soft Computing Journal, vol. 9, no. 2, pp. 647-651, 2009.

[15] V. R. Uslu, C. H. Aladag, U. Yolcu, and E. Egrioğlu, "A new hybrid approach for forecasting a seasonal fuzzy time series," in Proceedings of the International Symposium Computing Science and Engineering Proceeding Book, pp. 1152-1158, 2010.

[16] F. Alpaslan, O. Cagcag, C. H. Aladag, U. Yolcu, and E. Egrioglu, "A novel seasonal fuzzy time series method," Hacettepe Journal of Mathematics and Statistics, vol. 41, no. 3, pp. 375-385, 2012.

[17] S. Aladag, C. H. Aladag, T. Mentes, and E. Egrioglu, "A new seasonal fuzzy time series method based on the multiplicative neuron model and SARIMA," Hacettepe Journal of Mathematics and Statistics, vol. 41, no. 3, pp. 337-345, 2012.

[18] E. Egrioglu, U. Yolcu, C. H. Aladag, and C. Kocak, "An ARMA type fuzzy time series forecasting method based on particle swarm optimization," Mathematical Problems in Engineering, vol. 2013, Article ID 935815, 12 pages, 2013.
[19] H. E. Hurst, "Long-term storage capacity of reservoirs," Transactions of the American Society of Civil Engineers, vol. 116, pp. 770-779, 1951.

[20] M. Li and W. Zhao, "On $1 / f$ noise," Mathematical Problems in Engineering, vol. 2012, Article ID 673648, 22 pages, 2012.

[21] M. Li and W. Zhao, "Visiting power laws in cyber-physical networking systems," Mathematical Problems in Engineering, vol. 2012, Article ID 302786, 13 pages, 2012.

[22] M. Li, "Fractal time series: a tutorial review," Mathematical Problems in Engineering, vol. 2010, Article ID 157264, 26 pages, 2010.

[23] H. E. Stanley, S. V. Buldyrev, A. L. Goldberger, S. Havlin, C.-K. Peng, and M. Simons, "Long-range power-law correlations in condensed matter physics and biophysics," Physica A, vol. 200, no. 14, pp. 4-24, 1993.

[24] G. Werner, "Fractals in the nervous system: conceptual implications for theoretical neuroscience," Frontiers in Fractal Physiology, vol. 1, article 15, 28 pages, 2010.

[25] J. Beran, "Statistical methods for data with long-range dependence," Statisticla Science, vol. 7, no. 4, pp. 404-416, 1992.

[26] P. C. Ivanov, L. A. Nunes Amaral, A. L. Goldberger et al., "From $1 / \mathrm{f}$ noise to multifractal cascades in heartbeat dynamics," Chaos, vol. 11, no. 3, pp. 641-652, 2001.

[27] B. Podobnik, D. Horvatic, A. L. Ng, H. E. Stanley, and P. Ch. Ivanov, "Modeling long-range cross-correlations in twocomponent ARFIMA and FIARCH processes," Physica A, vol. 387, no. 15, pp. 3954-3959, 2008.

[28] M. Zevallos and W. Palma, "Minimum distance estimation of ARFIMA processes," Computational Statistics \& Data Analysis, vol. 58, pp. 242-256, 2013.

[29] R. J. Bhansali and P. S. Kokoszka, "Prediction of long-memory time series: a tutorial review," in Processes With Long-Range Correlations, vol. 621 of Lecture Notes in Physics, pp. 3-21, 2003. 


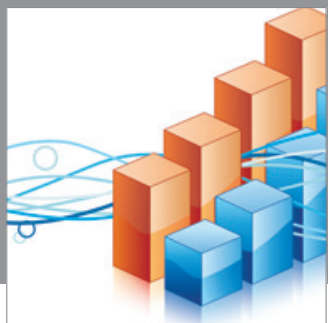

Advances in

Operations Research

mansans

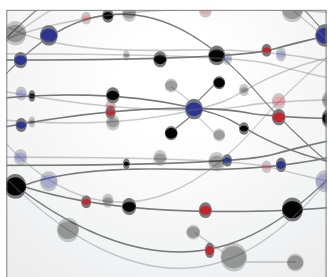

The Scientific World Journal
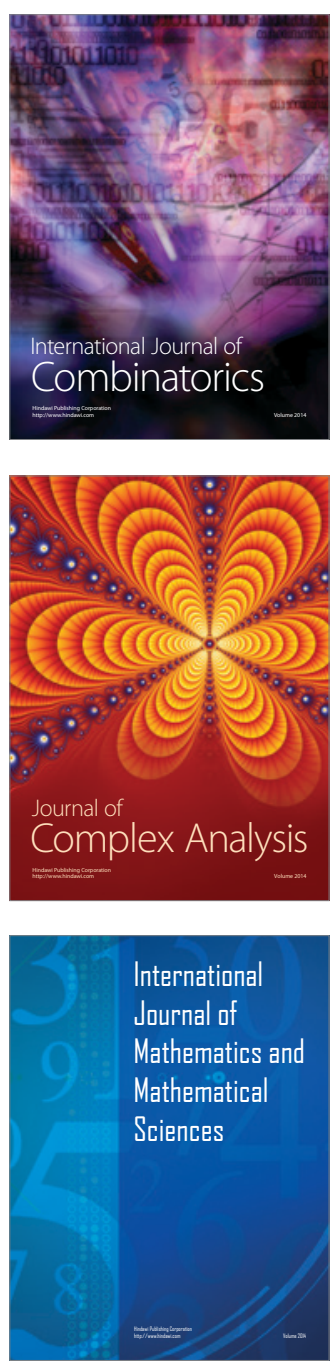
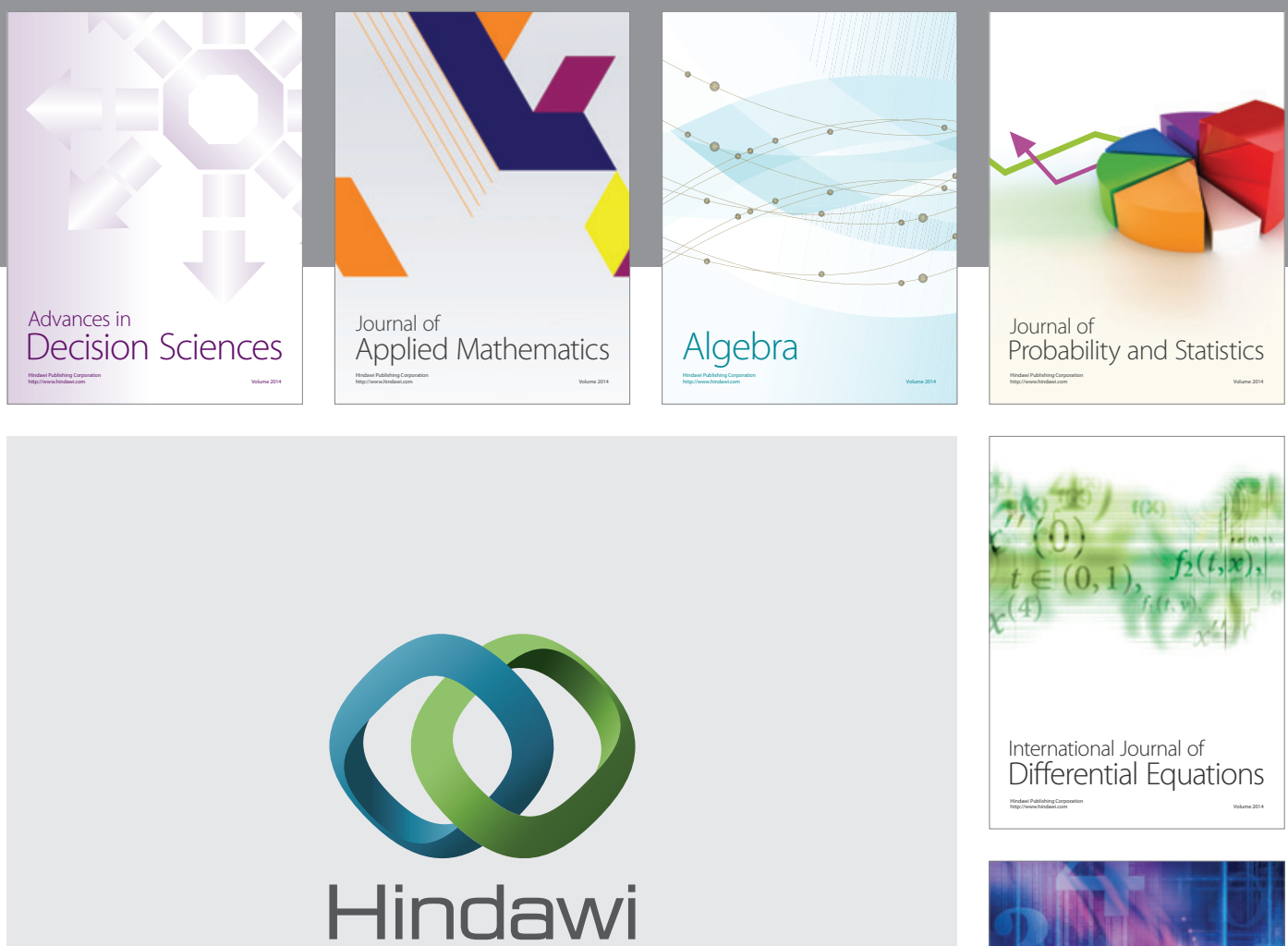

Submit your manuscripts at http://www.hindawi.com
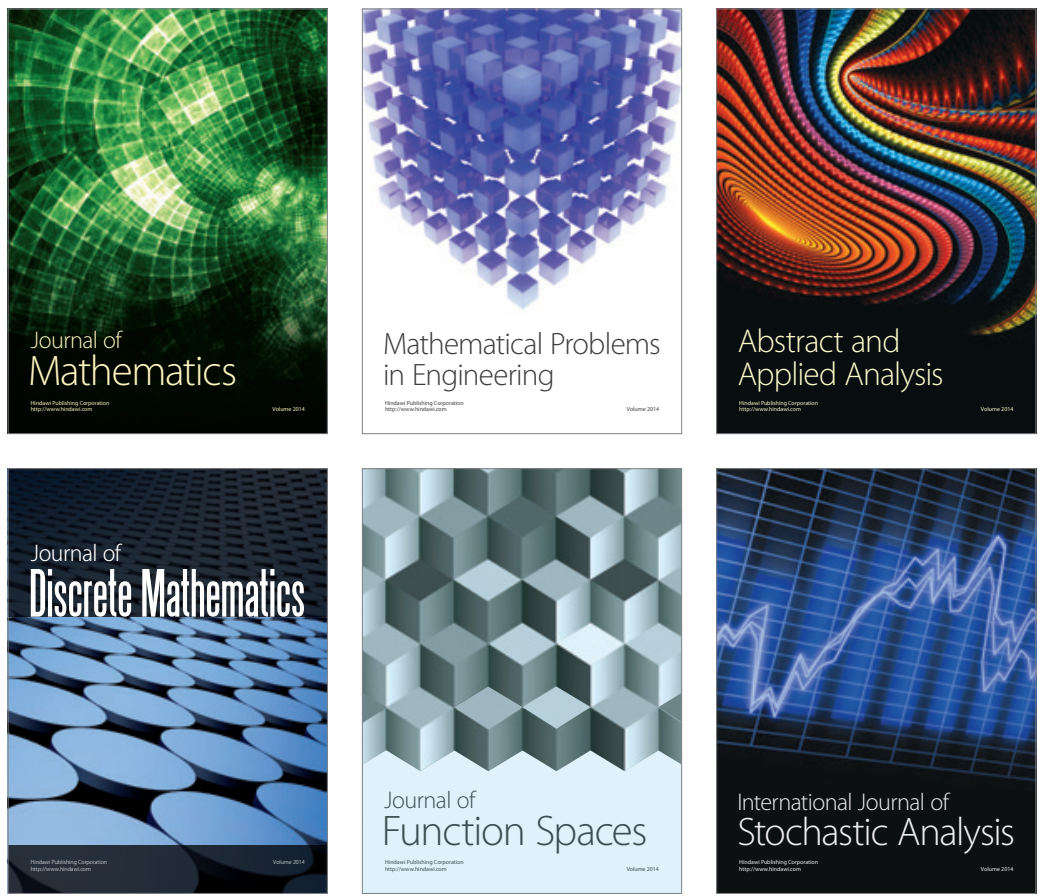

Journal of

Function Spaces

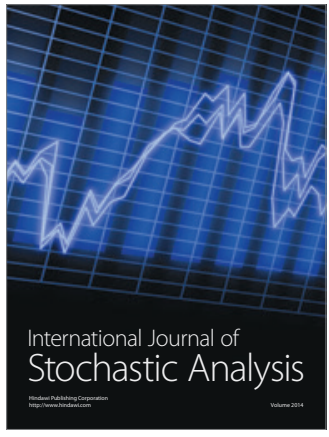

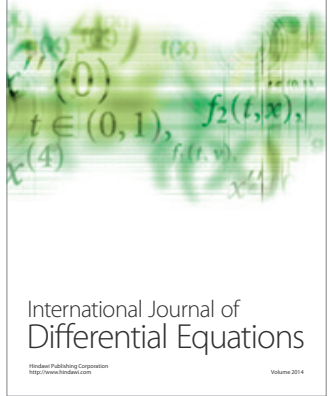
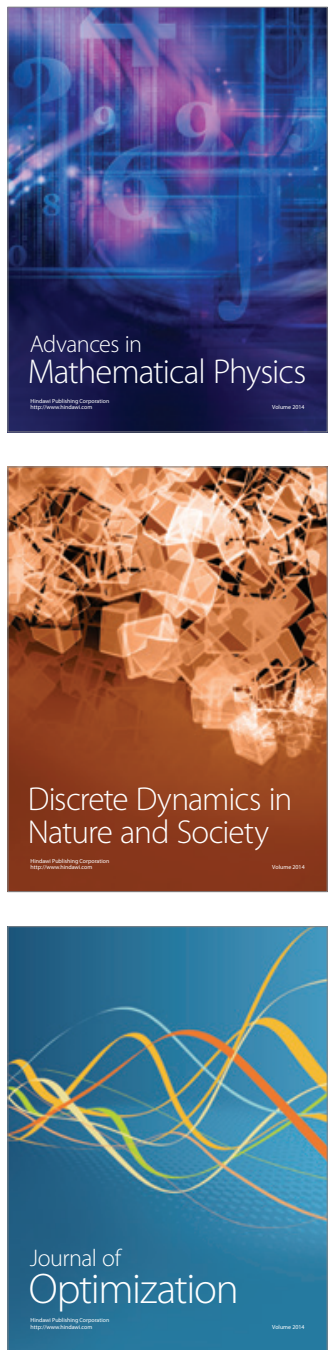